Revista de la red interuniversitaria de estudios sobre las literaturas rioplatenses contemporáneas en Francia

21 | 2020

Glosolalias transplatinas: fantasmas, utopías y

ficciones lingüísticas

\title{
El signo ebrio:El árbol de Saussure de Héctor Libertella
}

Le signe ivre: El árbol de Saussure d'Héctor Libertella

The Drunken Sign: On El árbol de Saussure by Héctor Libertella

Diego Vecchio

\section{CpenEdition}

Journals

Electronic version

URL: http://journals.openedition.org/lirico/9793

DOI: $10.4000 /$ lirico. 9793

ISSN: 2262-8339

Publisher

Réseau interuniversitaire d'étude des littératures contemporaines du Río de la Plata

\section{Electronic reference}

Diego Vecchio, «El signo ebrio:El árbol de Saussure de Héctor Libertella», Cuadernos LIRICO [En línea]

21 | 2020, Publicado el 13 julio 2020, consultado el 29 enero 2021. URL: http://

journals.openedition.org/lirico/9793 ; DOl: https://doi.org/10.4000/lirico.9793

This text was automatically generated on 29 January 2021.

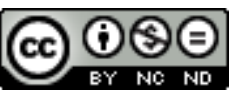

Cuadernos LIRICO está distribuido bajo una Licencia Creative Commons Atribución-NoComercialSinDerivar 4.0 Internacional. 


\title{
El signo ebrio:El árbol de Saussure de Héctor Libertella
}

\author{
Le signe ivre: El árbol de Saussure d'Héctor Libertella \\ The Drunken Sign: On El árbol de Saussure by Héctor Libertella
}

\section{Diego Vecchio}

\section{Literal}

1 El 12 de marzo de 1964, el adelantado Oscar Massotta lee en el instituto de psiquiatría social de Pichon Rivière una comunicación intitulada "Jacques Lacan o el inconsciente en los fundamentos de la filosofía" que marca no solamente la entrada sigilosa de la teoría lacaniana en el mundo hispano, sino que también anuncia las nupcias entre las letras y el inconsciente que se celebraría una década más tarde, con el lanzamiento en 1973 del primer número de Literal. Libertella recuerda:

Revista de culto, si las hubo, Literal, como Martin Fierro en la década del '20, ejerció una extraña influencia en la Argentina de los setenta. Traía una novedad perversa: el lento destilado del psicoanálisis en la literatura, que unos años antes, de la mano de Oscar Masotta, producía la hibridez de un cruce entre el inconsciente y la letra" (2002: 5).

Las similitudes que existen entre Martín Fierro y Literal no tendrían que eclipsar las divergencias. El corte que introduce Literal en los años 70 revierte y vuelve obsoleto el corte que pudo haber introducido Martin Fierro en los años 20. A diferencia de las vanguardias europeas, norteamericanas o brasileñas, las vanguardias argentinas fueron reticentes, por no decir hostiles, al descubrimiento freudiano. Borges o Macedonio Fernández que hacen de la nadería de la personalidad y de la crítica de la psicología del yo una de las consignas del programa, leen con fervor a Hume, Berkeley, Schopenhauer y William James, pero no a Freud. Medio siglo más tarde, en los años 70, Literal aspira recuperar medio siglo perdido, anunciando los esponsales de las letras y el inconsciente, gracias a los cantos de sirenas sibilinas de Lacan. 
3 Entre los colaboradores de Literal, la cantidad y calidad del psicoanálisis en la sangre varió según los individuos. Hubo abstemios empedernidos que permanecieron impermeables a la novedad y a la perversión. Hubo otros que bebieron hasta la médula, aunque no siempre los grandes bebedores fueron quienes mejor lo absorbieron. Está probado que los resultados más interesantes del cóctel se obtuvieron cuando los alcoholes lacanianos se mezclaron con otros ingredientes.

\section{El árbol de Saussure}

4 Huellas de esta hibridez son perceptibles, un cuarto de siglo más tarde; en El árbol de Saussure de Héctor Libertella. El título remite a una de las páginas más conocidas del Curso de lingüística general de Ferdinand de Saussure, donde se puede leer, en capítulo 1 de la primera parte:

5 "El signo lingüístico es, pues, una entidad psíquica de dos caras, que puede representarse por la siguiente figura:



6 Estos dos elementos están íntimamente ligados y se reclaman recíprocamente.

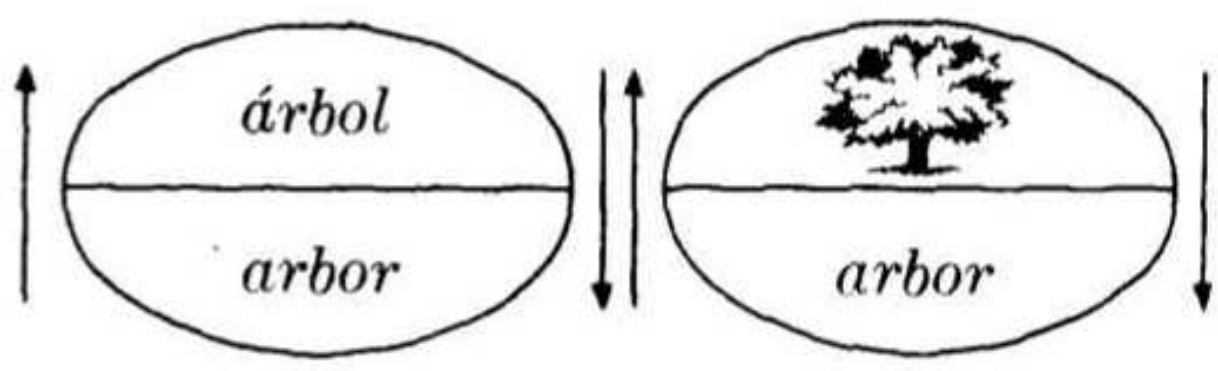

7 Ya sea que busquemos el sentido de la palabra latina arbor o la palabra con que el latín designa el concepto de árbol, es evidente que las vinculaciones consagradas por la lengua son las únicas que nos aparecen conformes con la realidad, y descartamos cualquier otra que se pudiera imaginar" (2007: 92).

8 Una evocación tan directa, en un autor tan oblicuo como Libertella, no es un detalle menor. Saussure, parece ser, habría introducido en la historia de los saberes un corte epistemológico que habría hecho posible el advenimiento de una ciencia de la lengua, no exento de efectos sobre las otras ciencias y las letras. Para bien y para mal, el corte casi siempre resulta amortiguado, digerido y domesticado en rumor. La doxa saussuriana del signo lingüístico se podría resumir en tres principios.

9 Uno: el signo es una entidad puramente psíquica que, en lugar de remitir a un referente o a una cosa, asocia un elemento semántico (el concepto) y un elemento fonético (la 
imagen acústica suscitada por los sonidos), o si se prefiere, un significado y un significante. No hay significado sin significante ni significante sin significado. Son como el reverso y anverso de una misma hoja de papel (137). Dos: el signo lingüístico es arbitrario. La asociación entre significante y significado no es una relación necesaria o motivada, sino un encuentro contingente y fortuito. Tres: el signo lingüístico es diferencial. La lengua es un sistema de signos en que todos los elementos son solidarios entre sí y el valor de un elemento no resulta más que de la presencia simultánea de los otros elementos. Un signo no tiene ninguna identidad en sí mismo, sino en relación con otros signos. Un signo es lo que los otros signos no son.

El Curso de lingüística general fue publicado póstumamente en 1916, a partir de los apuntes que Charles Bally y Albert Sechehaye tomaron de las lecciones impartidas por Saussure entre 1906 y 1911. Publicado en medio de la Primera Guerra Mundial, el Curso pasó casi desapercibido. Pero nunca se sabe muy bien adónde puede llegar un libro y qué tipo de licor puede llegar a destilar tras varias décadas de maceración. Saussure nunca habría sospechado, como así tampoco sus discípulos, que, medio siglo más tarde, la lingüística iba a ser considerada como modelo de las ciencias humanas; el Curso, un libro fetiche y su definición del signo lingüístico, mutatis mutandis, uno de los conceptos claves del psicoanálisis, disciplina contemporánea que en vida ignoró por completo.

\section{Los toilettes de Lacan}

11 En 1957, Lacan pronuncia en el anfiteatro Descartes de la Sorbona, ante un grupo de estudiantes, una conferencia, publicada en sus Écrits (1966), con el título de "Instance de la lettre dans l'inconscient ou la raison depuis Freud”. Según Lacan, que leyó a Koyré, que comentó a Galileo, para que haya ciencia moderna, no basta con recortar un objeto empírico, sino que también hace falta un algoritmo, concebido menos como una fórmula de medición y cálculo que como una escritura formal. Así Saussure habría fundado la lingüística como disciplina científica, al inventar el siguiente algoritmo del signo lingüístico:

$$
\frac{S}{s}
$$

12 En ambas letras hay que leer: "un significante sobre un significado; en que sobre designa la barra que separa ambas etapas" (2002: 464). Lacan atribuye este algoritmo a Saussure, no sin reconocer que este esquema no se encuentra en ninguna de las páginas del Curso de lingüística general. En realidad, entre el signo lingüístico de Sassure y el algoritmo que le es atribuido por Lacan hay varias divergencias.

Si Saussure considera el signo como una entidad indivisible que reúne un significante y un significado, anverso y reverso de una misma hoja; Lacan insiste, por su lado, en la separación radical entre ambos elementos. De ahí el énfasis que pone en la barra, concebida como una barrera y una resistencia entre ambos órdenes. El algoritmo lacaniano serrucha, por así decir, el árbol de Saussure. Y no solo esto. Si en el árbol de Saussure el significado está encima del significante; en el algoritmo lacaniano, por el contrario, el significante aparece en la parte superior y con mayúscula; y el significado, en la parte inferior y con minúscula y cursiva. En Lacan el significante ejerce una 
supremacía sobre el significado; no en Saussure, que considera a ambos elementos como simétricos y correlativos.

Esta inversión no deja de tener efectos sobre la producción de la significación, que deja de ser un vínculo estable entre un significante y un significado. Para Lacan, un significante nada significa en sí mismo, sino en relación con otros significantes, en una cadena de marcas diferenciales, según un doble movimiento: deslizamiento metonímico de un significante hacia otro significante y substitución metafórica de un significante por otro significante. La significación se precipita cuando estos movimientos se interrumpen en lo que Lacan llama, según un término de tapicería, un punto de almohadillado (un point de capiton). En otras palabras, la significación se produce cuando la cadena de significantes y la cadena de significados se abrochan o se abotonan en un punto. La significación es precaria: está prendida con alfileres.

Para dar cuenta de las divergencias entre psicoanálisis y lingüística, Lacan propone sustituir el árbol Saussure por esta figura:

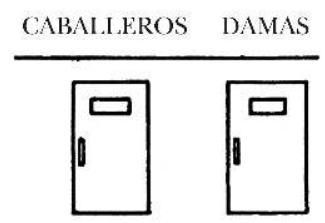

FIgURA 2

(220: 467)

Este esquema da a ver:

dos puertas gemelas que simbolizan el recinto ofrecido al hombre occidental para satisfacer sus necesidades naturales fuera de casa, el imperativo que parece compartir con la gran mayoría de las comunidades primitivas y que somete su vida pública a las leyes de la segregación urinaria (467).

Los toilettes de Lacan introducen varios cambios en relación al esquema de Saussure. En la parte superior de la figura, no hay un solo significante en singular (arbor) sino dos y en plural (caballeros y damas). Una vez más: los significantes no están solos y aislados, sino que forman una cadena de marcas diferenciales. En la parte inferior, en lugar de la imagen de un hombre y una mujer que ilustrarían ambos significantes (a la manera del dibujo del árbol que ilustra arbor), el esquema presenta dos puertas gemelas, que nada permite distinguir. Lacan afirma que ambas puertas simbolizan las leyes de segregación urinaria. La significación no sería ajena a la diferencia sexual. El significante entra, por así decir, en el significado. El sentido es algo que se precipita y que cae - no se sabe muy bien dónde.

Desde luego, existen diferencias, para la lingüística, entre el sentido, el significado y el símbolo. La terminología flotante de Lacan le permite saltar con la misma soltura de una noción a la otra y de la epistemología a la lingüística y luego, no sin humor, de la lingüística a la tapicería o a la escatología. Al adoptar el tic estructuralista de reverenciar a la lingüística como disciplina soberana de las ciencias humanas, Lacan en realidad la destituye. ¿Los toilettes de Lacan no son acaso una boutade sobre el árbol de Saussure?

De hecho, para Lacan se trata no tanto de lingüística sino de lingüistería (1975: 20). El matiz despectivo del sufijo -ía, que también se encuentra en piratería, hace pensar en una disciplina que no respetaría los buenos modales que exigen la ciencia, los 
diccionarios y el sentido común. Estas diversas mutaciones que sufre el árbol de Saussure ponen de manifiesto las diferencias epistemológicas que opone la lengua del lingüista y la lengua del psicoanalista. No se trata del mismo objeto.

La lengua de la lingüística es una lengua que en el fondo nadie habla. Es verdad que Saussure distingue entre la lengua y el habla. Pero esta distinción corresponde al aspecto social o individual del lenguaje. Es verdad también que la lingüística intentó pensar el sujeto a partir de la noción de enunciación. Pero aun así, el sujeto es concebido como un puro punto de emisión, sin división, que codifica un mensaje destinado a otro sujeto que lo descodifica, concebido también como un puro punto de recepción, sin escisiones.

La lingüística es la ciencia de la lengua y la lengua es un sistema de signos, sin sujeto, sin deseo, sin inconsciente. Para la lingüística saussuriana, la lengua es una totalidad en sí, homogénea y consistente. Al pensar la lengua junto a la noción de inconsciente, irrumpe una heterogeneidad que pone en jaque esta totalidad. Hay lenguas que no son como las otras, y que por su diferencia, introducen una incompletud en el conjunto. Piénsese en la lengua materna; en la lengua del equívoco, del lapsus y del chiste; en los balbuceos y vocalizaciones del lactante; en las glosolalias místicas, psicóticas o artísticas. Para nombrar esta lengua, que no puede ser incluida con las otras lenguas sin desbaratar la totalidad y amenazar su consistencia, Lacan inventa, a partir de un lapsus, un neologismo: la lalangue (1975: 126).

\section{El signo ebrio}

Literal fue uno de los principales alambiques donde fueron destilados los alcoholes del psicoanálisis en la cultura argentina. El árbol de Saussure de Libertella, probablemente uno de sus licores más refinados, se inscribe en una genealogía, saussureana y lacaniana, probablemente más lacaniana que saussuriana, referencias un tanto anacrónicas y obsoletas, hay que reconocerlo, para el año 2000 en que fue publicado. Ficción teórica que entra en escena cuando la novedad perversa del estructuralismo francés y el psicoanálisis lacaniano, ya habían perdido gran parte de su efervescencia, $E l$ árbol de Saussure no puede abordar el concepto de signo lingüístico sino con distancia y desde el equívoco.

En Libertella, Saussure y Lacan no son autoridades que hay que venerar o comentar, ni teorías para aplicar (y aplastar) a las letras, sino cajas fuertes que se pueden asaltar para fabricar con el botín literatura. El escritor sería, según Libertella, alguien "que cruza y atraviesa en diagonal, como un alfil, la fortaleza de las disciplinas constituidas para llevar y traer herramientas y preguntas de un lado para el otro. Alguien que entresaca un poco de psicoanálisis de acá y lo lleva allá donde los signos no entienden cómo dicen qué" (1993: 28).

En El árbol de Saussure de Libertella, las referencias a la teoría del signo lingüístico y al algoritmo lacaniano son laterales, oblicuas y sobre todo humorísticas. Basta con leer la primera sección, intitulada "La barra del bar":

Con los codos apoyados en la barra de metal, los parroquianos del ghetto miran con mirada boba el único árbol de la plaza, sin imaginar siquiera que el bar donde se encuentran proviene, casualmente de "barra".

En sus ojos no se refleja un árbol tal como lo pensamos, sino apenas un tronco con ramas y hojas; algo que solo dice: acá estoy (estoy acá). 
Mientras beben, miran. Y mientras miran no saben que esa figura les determina un punto de vista -los va distribuyendo silenciosamente en sus butacas (15).

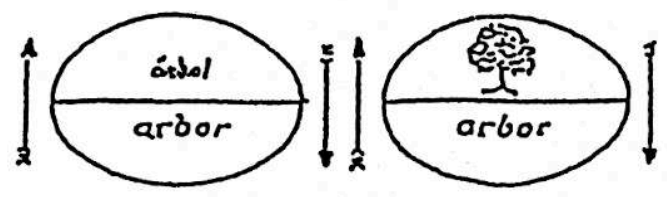

\section{FIgURA 3}

(2000: 15)

Lo que importa aquí no es tanto lo que se dice, sino lo que se muestra: un chiste del chiste. La barra ya no designa aquello que une de manera indisoluble dos entidades psíquicas (el árbol de Saussure) ni un corte que separa los significantes del significado (les toilettes de Lacan) sino, de manera mucho más concreta y prosaica, el mostrador de un bar donde un grupo de parroquianos bebe, mirando bobaliconamente un árbol. Si de Saussure a Lacan, el árbol lingüístico se vuelve esquema escatológico; de Lacan a Libertella, el esquema escatológico se vuelve árbol etílico. Esta deriva es posible gracias a la homofonía que existe en francés entre barre (barra) y bar (bar) y a los equívocos a los que se presta su traducción al español. Barre quiere decir barra, raya, asta, línea, barrera, estrado, travesaño, pero no mostrador, que se dice comptoir. El signo ebrio nace de estas derivas.

¿Qué le ocurre a la literatura cuando el signo se disloca; cuando la barra en lugar de unir, separa; cuando el significante remite ya no al significado sino a otro significante; cuando el sentido se produce como un efecto de deslizamiento y fuga más que de correspondencia y correlación? En otras palabras, ¿qué ocurre cuando las letras se cruzan con el lenguaje y el inconsciente? A estas preguntas, Josefina Ludmer, una de las bebedoras de Literal, responde: "Leo las cien páginas de El árbol de Saussure: una utopía y quedo fascinada, pero no entiendo nada" (2000: 95).

En las ficciones teóricas de Libertella, no hay argumentos que desplegar, ni conceptos que construir, ni historias que narrar y por eso mismo, nada que entender, nada que interpretar, nada que descifrar. El signo ebrio zigzaguea, tambalea y trastabilla. En esta caída, el sentido se produce como una chispa en medio de la opacidad de las letras. Fascina, pero a la vez se escabulle. Ejerce cierta seducción, pero sobre todo, suscita perplejidad. Tal vez esta sea una de las utopías que promete el subtítulo: una utopía lingüística, la utopía del sentido, la utopía del signo ebrio.

Desde esta perspectiva, la literatura podría ser concebida como una charla entre parroquianos que beben en la barra de un bar, a veces llamado ghetto y otras veces tribu. ¿Pero qué tipo de charla? La literatura no es una charla como las otras, con un sujeto, concebido como un punto indivisible, que cifra un mensaje destinado a otro sujeto, también concebido como un punto indivisible, que lo descifra. Nada más alejado de esta utopía que los postulados de la teoría de la recepción o de la hermenéutica, que piensan la literatura en términos de colaboración, adecuación, correspondencia entre un autor y un lector. La literatura sería la charla del signo ebrio. Lo que pone en relación a los parroquianos es el desencuentro, el desajuste, la incomprensión recíproca. "Cuando conversan en la barra del bar, los parroquianos de este libro no se entienden. Cada uno es el programa indescifrado del vecino de butaca" (60). 

lo contrario de lo que quieren decir, que dicen lo que otro no dijo, que dicen algo que no se entiende. No es sorprendente que a la barra del bar se arrimen tantos escritores virtuales y apócrifos, cuya existencia se reduce a un par de citas, como es el caso de Jean Pol, Ch. E. Atterton, Giorgio Lini, Ethan Sterne, Winfried Hassler, Thomas Sfez o Clovis Carvalho, que se pregunta: “¿Cuántos de los viejos e inmortales autores que cité no nacieron aún y para hacerlos presentes tuve que escribir por ellos sus libros?" (44). La utopía del signo ebrio produce, entre otros efectos, una comunidad espectral. Como el bebedor, el escritor fantasma, es un sujeto descentrado. El fantasma es "lo que está siempre que no esté" (2006: 24): el muerto que vuelve al mundo de los vivos, la aparición como retorno de lo desaparecido, la presencia de lo no presente, el ser-ahí de lo que está ausente.

\section{Lengua marciana y sanscritoide}

31 Vuelvo a Ginebra y vuelvo a principio del siglo XX, para explorar otros cruces posibles entre el inconsciente y las letras. En el año 1900, mientras Freud publica en Viena la Interpretación de los sueños, Théodore Flournoy da a conocer en Ginebra De las indias a Marte: estudio sobre un caso de sonambulismo con glosolalia. Como muchos científicos de las postrimerías del siglo XIX, Flournoy se interesa en los fenómenos mediúmnicos y redacta esta monografía sobre el caso de Hèlene Smith (en la vida real Catherine-Elise Müller), que acepta poner sus talentos espectrales al servicio de la ciencia.

Al caer en estado de trance, Hèlène Smith no hace hablar al espíritu de Platón, Cleopatra, Juana de Arco o Napoleón, como tantos otros médiums, sino que prefiere viajar, guiada por su espíritu tutelar, a comarcas lejanas en el espacio y en el tiempo, como la corte de Luis XVI, la India o Marte, aprovechando sus existencias anteriores. Hélène Smith afirma haber sido, en el siglo XV, Simandini, la hija de un jeque árabe, al que abandona al convertirse en la decimoprimera esposa del príncipe Sivourka Nayaka, señor de Kanata, en la India; en el siglo XVIII, la desafortunada Marie-Antoinette; y en el siglo XIX, una modesta empleada de comercio de Ginebra, que sin embargo logra viajar hasta el planeta Marte para penetrar sus misterios y revelarlos a la humanidad.

Estas travesías transespaciales, transhistóricas y transplanetarias forman lo que Flournoy no vacila en llamar una novela, organizada en tres ciclos: el ciclo real, el ciclo hindú y el ciclo marciano. Lo que más le llama la atención no son tanto los personajes, los decorados ni las intrigas que urde Hélène Smith, sino ciertas invenciones lingüísticas. El sonambulismo de Mlle Smith está acompañado de glosolalias. En el siglo XIX, el término ya no designa un carisma del Espíritu, sino la producción de neologismos durante un estado de eclipse de la conciencia. Dos tipos de fenómenos glosolálicos se distinguen en estas novelas mediúmnicas: por un lado, la invención de la lengua que hablan los habitantes del planeta Marte (versión espiritista de la lengua de

Cuadernos LIRICO, 21 | 2020 
los ángeles); y por el otro, el empleo de algunas palabras de sánscrito, lengua natural que Hélène Smith en principio ignora por completo, pero que la princesa Samandini hablaba corrientemente (versión espiritista del don de lenguas).

Mucho menos populares que las sesiones de hipnosis de Charcot en el anfiteatro de la Salpêtrière, aunque no por ello menos espectaculares, las sesiones de Hélène Smith están abiertas a un grupo selecto de invitados, sobre todo hombres de ciencia, entre los cuales figuran Ferdinand de Saussure, titular de la cátedra de sánscrito y lenguas indoeuropeas de la universidad de Ginebra. Flournoy, que desconoce por completo las lenguas de la India, lo consulta para conocer su opinión respecto a los neologismos del ciclo hindú: ¿esta lengua sin sentido tiene algún sentido en relación al sánscrito?

Tras un análisis pormenorizado de los mensajes glosolálicos de Mlle Smith, Saussure concluye que no se trata de sánscrito propiamente dicho, aunque tampoco de nada que le fuera contrario. La lengua de Mlle Smith es una jerigonza en la cual es posible reconocer, de tanto en tanto, algunas palabras que presentan cierto parecido con el sánscrito: en otros términos, una lengua sanscritoide.

Saussure se toma muy en serio este trabajo de peritaje lingüístico, tal vez demasiado en serio, a tal punto que en determinado momento se pregunta cómo es posible que la princesa Samandini, a través de la boca de Hélène Smith, hablara sánscrito, lengua noble y culta, de uso exclusivamente masculino, en lugar de páncrito, lengua vulgar y popular, al alcance de todos y de todas. Recuerda que cuando un rey se dirigía a su esposa en sánscrito, la esposa le respondía en páncrito. Parece escrutar esta lengua espectral como si fuera una lengua natural.

El sanscritoide de Hélène Smith responde a algunas reglas de composición. La glosolalia hindú hace caso omiso de la gramática del sánscrito y desconoce por completo la existencia de declinaciones. La similitud es sobre todo léxica, es decir, significante. Para inventar palabras con un aire de familia sanscritoide, el procedimiento es muy simple. Hélène Smith tiene una neta preferencia por la $a$, la vocal más frecuente del sanscrito; casi nunca se aventura con palabras que tuvieran más de dos o tres sílabas o que presenten grupos consonánticos. Saussure observa que a veces los significantes sanscritoides coinciden con significantes sánscritos, asociados a sus respectivos significados. Pero hay un hecho por encima de los otros que lo asombra. El sanscritoide de Hélène Smith ignoran la $f$, fonema inexistente en sanscrito. Dado que existe una posibilidad en veinte para omitir la $f$, este hecho no ha de ser considerado como un mero producto del azar.

Victor Henry, un lingüista contemporáneo de Saussure, ve en la omisión de la $f$ una referencia a français. Al caer en estado de trance, Hèlène Smith procura inventar una lengua lo más alejada posible de su lengua materna, para producir un efecto de extrañeza. El sanscritoide sería francés disfrazado de anti-francés. Nada impide ver, por otro lado, en la ausencia de $f$ una referencia a femme. Al fabricar el sancritoide, la médium se apodera de una lengua sagrada de uso exclusivamente masculino. Frente al poder del lingüista y el psicólogo que estudian su sonambulismo con glosolalias, Mlle Smith opone su poder de producir y traducir lenguas cuyo sentido se les escapa. También sería posible pensar en fantôme. El sanscritoide es una lengua espectral hablada por una princesa hindú, fallecida hace quinientos años, que retorna al mundo de los vivos.

Por lo visto, las glosolalias de Hélène Smith plantean más problemas que certezas. Flournoy se pregunta ¿cómo se explica que una empleada de comercio haya 
reproducido un rasgo tan especifico del sánscrito, sin conocer el sánscrito? ¿Cómo explicar que en determinadas circunstancias, ciertos sujetos puedan hablar una lengua natural que nunca aprendieron? Para Flournoy se trata de un caso de criptemnesia, esto es, de recuerdos latentes que irrumpen en un estado de conciencia segunda, como el que puede observarse en el sueño, el sonambulismo o el trance mediúmnico. Supone que Hèlene Smith pudo haber oído en algún momento de su vida ginebrina a un estudiante de sánscrito, cuando repasaba en voz alta las conjugaciones en un cuarto vecino y sin saberlo, memorizó algunas palabras. 0 que tal vez hojeó una gramática o un manual de sanscrito y retuvo algunas palabras, olvidándose por completo de este hecho. Flournoy se inclina a favor de esta última conjetura. Hélène pronuncia la $u$ del sanscrito a la manera de una $u$ francesa, como si estuviera leyendo un libro sin conocer las reglas fonéticas y no como si estuviera repitiendo algunas palabras extranjeras, oídas al pasar.

Esta hipótesis presupone la existencia de fragmentos de la psique que escaparían a la jurisdicción del Yo. No se trata del inconsciente de Freud, que se manifiesta en el retorno de ciertas representaciones expulsadas de la consciencia, como ocurre en los actos fallidos, los chistes, los sueños y los síntomas. Tampoco del subconsciente de Janet, que irrumpe cuando, por un problema de síntesis, ciertas percepciones, recuerdos y pensamientos se desprenden de la conciencia principal, organizándose en una conciencia paralela. En Hélène Smith no trata de una degradación, sino por el contrario de una ampliación de sus facultades normales.

Flournoy adhiere a la teoría del Yo subliminar de Frederic Myers, que concibe al inconsciente como un espacio sumergido, definido por una frontera flotante, que va y viene, como las mareas. Del mismo modo que existen rayos ultrarrojos y ultravioletas que son invisibles para el ojo humano, así también existen estados psíquicos que escapan a la conciencia, aunque no por ello inexistentes. Para Myers y Flournoy, las facultades son dobles. Existe una memoria más allá de la memoria, pensamientos más allá del pensamiento, percepciones más allá de la percepción, voluntad más allá de la voluntad, lenguas más allá de las lenguas que hablamos y conocemos. Durante el estado de trance, se habría despertado en la médium "el poeta muerto" que todos llevamos dentro. No es de extrañar que Hélène Smith se haya convertido en una de las heroínas veneradas por los surrealistas y en un ejemplo del arte bruto.

\section{Anagramas}

El análisis del sanscritoide de Hèlène Smith no resulta totalmente ajeno a las investigaciones que absorben la atención de Saussure, entre 1906 y 1909, sobre los anagramas en la poesía indoeuropea. Todo comienza por una intuición de Saussure al descubrir dos principios que parecerían regir la composición de ciertos versos latinos. El primero es un principio numérico que estipula que los fonemas del verso han de aparecer dos veces. El segundo es un principio temático que postula que los fonemas del verso son seleccionados en función del nombre propio de una persona o divinidad. En el epitafio inscripto en el sarcófago de Lucius Cornelius Scipio, por ejemplo, se puede leer: "Taurasia Cisauna Samnio cepit". Este verso contiene, diseminados, los fonemas del nombre propio Scipio, presentes en las silabas ci (CIsauna), pi (cePIt) y io (SamnIO) (Starobinsky 1971: 29). 
Lacan recuerda que barre [barra] es el anagrama de arbre [árbol] $(2002,471)$. Se podría decir que el anagrama en la poesía indoeuropea introduce los efectos de la barra en el árbol de Saussure, descerrajando el cepo del signo lingüístico, disociando significante y significado, poniendo en evidencia el funcionamiento autónomo del significante, como ocurre en la homofonía, el lapsus, el chiste o las glosolalias.

44 Con la teoría de los anagramas, la lingüística científica parece transformarse en delirio o ficción lingüística. La profusión anagramática no tiene fin. El anagrama desborda el anagrama. Detrás del anagrama, siempre puede haber otro anagrama y detrás otro anagrama. Los anagramas están por todos lados, es decir, en ningún lado. En sus cuadernos, Saussure reconoce:

Quand une première anagramme apparait, il semble que ce soit la lumière. Puis, quand on voit qu'on peut en ajouter un deuxième, un troisième, un quatrième, c'est alors que, bien loin qu'on se sente soulagé de tous les doutes, on commence à n'avoir plus même de confiance absolue dans le premier : parce qu'on arrive à se demander si on ne pourrait pas trouver en définitive tous les mots possibles dans chaque texte (Starobinsky $1971: 132$ ).

Entre los cuadernos sobre los anagramas y el Curso de linguística general, hay algo que se desvanece: el sujeto. La lengua, en tanto objeto de la ciencia, se define como un sistema de signos sin sujeto. La teoría de los anagramas incluye aquello que es excluido, introduciendo una heterogeneidad en el objeto de la lingüística. Como en el caso del sanscritoide de Hèlène Smith, la diseminación de un nombre en la poesía indoeuropea plantea varios problemas. ¿Se tratada de un mero azar o existe en realidad una intención? Y si este fuera el caso, ¿se trata de una intención consciente o inconsciente? ¿O se trata más bien de un efecto de la interpretación? En definitiva, ¿qué relación entre las letras, el lenguaje y el inconsciente?

\section{El árbol hermético}

El árbol de Saussure es un retoño que crece al pie de otro árbol que Libertella presenta y comenta en la tercera sección de Las sagradas escrituras (1993): el árbol hermético. 


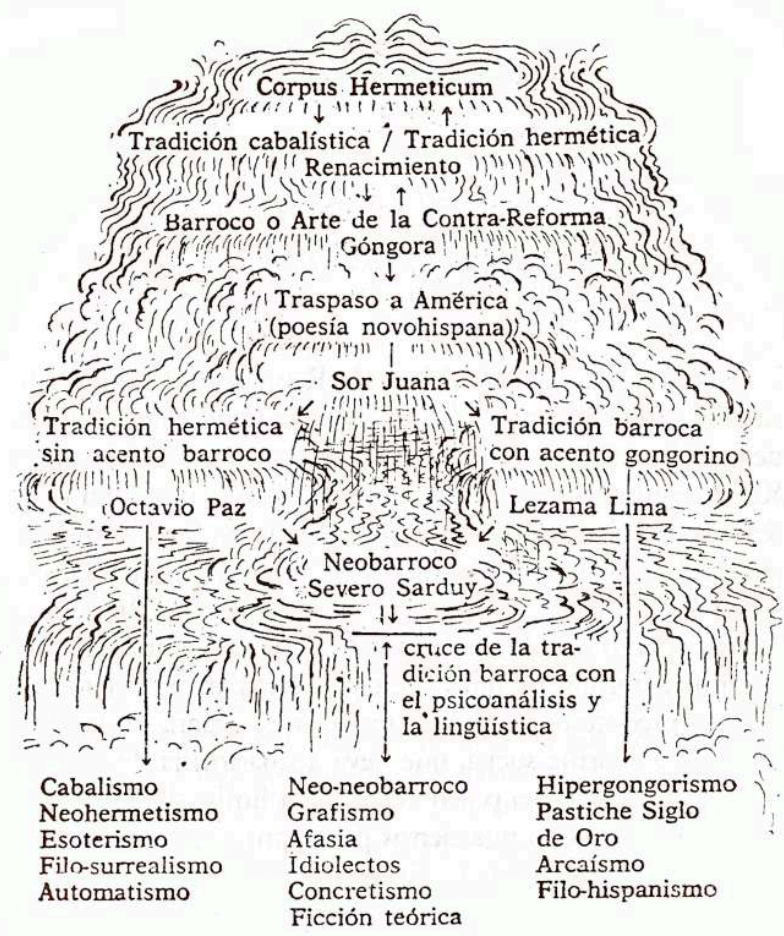

FIgURA

(LIBERTELLA 1993:71)

A propósito de esta ilustración, Libertella precisa:

Se trata de poner al día el retrato de una muy vieja familia; un diagrama que puede coincidir o no con la realidad, pero que tal vez coincida con lo real o verdadero de su literatura. Como si fuera un mapa donde el lector ancestral viene bajando bruscamente desde el macizo Corpus Hermeticum y éste se derramara, de pronto, en una multitud de formas que se confunden hoy en diferentes redes botánicas: desde el arcaísmo al hipergongorismo, del grafismo al concretismo, del grotesco a los idiolectos, al pastiche Siglo de Oro español, al filosurrealismo, y, por último, a la ficción teórica (67).

El árbol hermético es en realidad un árbol genealógico que da cuenta de ciertos parentescos, alianzas y filiaciones literarias. Libertella traza un mapa de cierta vanguardia latinoamericana, definida menos como ruptura de la tradición que como retorno y resurgimiento de "una vieja familia", un phylum donde inscribe su propia producción. El retrato de familia, como siempre, es una forma de autorretrato. Este diagrama de angustias de las influencias, con su régimen de flujos y corrientes, comienza en el Corpus Hermeticum y culmina en la ficción teórica que el mismo Libertella practica.

El árbol hermético está construido en torno a dos acepciones del término hermético. Hermético se dice de los textos sagrados atribuidos a Hermes, dios de las comunicaciones y del comercio, avatar griego del dios egipcio Toth, escriba de los dioses. El Corpus Hermeticum es, en realidad, un conjunto heteróclito de textos de astronomía, cosmología, teología, medicina, magia, alquimia, filosofía, física, historia natural, escritos entre el siglo II y el siglo III de nuestra era y traducidos del griego al latín, en los albores del Renacimiento, por Marsilio Ficino. Hermético se dice también de un escrito difícil, impenetrable, oscuro, en definitiva ilegible. Los textos del corpus 
Hermeticum, que pueden estar reservados a un círculo de iniciados, son esotéricos pero no necesariamente ilegibles; como así también no todos los textos ilegibles pertenecen al Corpus Hermeticum. El árbol hermético de Libertella se despliega en este equívoco que reúne las sagradas escrituras con las escrituras oscuras.

Un equívoco siempre lleva a otro equívoco. Aquello que permite reunir en un mismo árbol lo sagrado y lo oscuro de las escrituras es el término barroco, etiqueta que a fines del siglo XIX los historiadores del arte alemán comienzan a utilizar para designar un estilo pictórico que sucede al estilo renacentista y que, en un movimiento de deriva, termina nombrando un estilo literario, caracterizado por su dificultad. Las metáforas barrocas se presentan como acertijos, fundados en una correspondencia o correlación, entre palabras, cosas e ideas disímiles. El hermetismo barroco está fundado en la desemejanza. Mientras mayor sea la distancia que separa el sentido literal del sentido figurado, tanto mayor será la dificultad que ofrezca el acertijo, como también su agudeza. La oscuridad, que resulta un vicio abominable para los preceptistas del siglo XVII, para el poeta barroco aguza y estimula el ingenio del lector.

Góngora, que nunca se consideró barroco, es considerado el poeta barroco por excelencia. Tal como aparece representado en el árbol hermético de Libertella, el barroco gongorino es movedizo y no deja de trasladarse y metamorfosearse en el espacio y en el tiempo. En el siglo XVI, desembarca en América, con la poesía de Sor Juana y hace del arte de la contrarreforma, un arte de la contra-conquista. En el siglo $\mathrm{XX}$, retorna como vanguardia hermética, asociada a dos nombres (Lezama Lima y Severo Sarduy), como así también a varios tallos y brotes (hipergongorismo, pastiche del siglo de oro, arcaísmo, filo-hispanismo, grafismo, afasia, idiolecto, concretismo, ficción teórica).

Las proliferación de esta nomenclatura no tendría que hacernos perder de vista lo esencial. Como lo precisa Libertella, lo que importa en este árbol, no es tanto la coincidencia con la realidad, sino con lo real de la literatura. ¿De qué modo una práctica simbólica, como la literatura, indisociable del lenguaje, se relaciona con lo real? ¿Con qué real se las tiene que arreglar la literatura? Estas preguntas orientan la mirada hacia el pie del árbol, ahí donde convergen todas las corrientes, ahí donde vuelven a cruzarse las letras y el inconsciente, bajo la insignia del neobarroco.

\section{El neobarroco}

La invención de esta etiqueta es atribuida a Severo Sarduy, que en 1972 publica, en la compilación de César Fernández Moreno América Latina en su literatura, "El barroco y el neobarroco", un artículo-manifiesto donde intenta domesticar las derivas, abusos y torsiones infligidas a la noción de barroco, reduciéndolo a un esquema operativo que permitiría pensar algunas producciones literarias latinoamericanas de la segunda mitad del siglo XX. Para definir de manera acotada al barroco, Sarduy invoca tres criterios.

Uno: la desarticulación del signo lingüístico. Una vez más, Sarduy no hace más que reformular en términos estéticos la teoría del significante de Lacan. Al igual que el sueño, el lapsus, el chiste o el síntoma, el texto barroco establece un corte entre el significado y el significante, afirmando la primacía del significante sobre el significado. La significación se produce en un movimiento de deriva, según operaciones específicas como la sustitución, la proliferación o la condensación, donde es posible reconocer los 
dos mecanismos del sueño descriptos por Freud y reformulados por Lacan en términos retóricos, en un cruce con la lingüística de Roman Jacobson.

Dos: la reflexividad. El texto barroco es un texto que lleva el tatuaje de otros textos. Junto a Kristeva y Bajtín, Sarduy define al barroco como carnaval que corta y pega, reorganiza y desfigura, exagera y atenúa otros textos, hasta la tautología que consiste en citarse a sí mismo, a través de la multiplicación de mises en abîme.

Tres: la búsqueda infructuosa por definición de lo que Lacan llama objeto a. Sarduy escribe:

El espacio barroco es el de la superanbundancia y el desperdicio. Contrariamente al lenguaje comunicativo, económico, austero, reducido a su funcionalidad -servir de vehículo a una información - el lenguaje barroco se complace en el suplemento, en la demasía y la pérdida parcial de su objeto. 0 mejor: en la búsqueda, por definición frustrada del objeto parcial. El "objeto" del barroco puede precisarse; es ése que Freud, pero sobre todo Abraham, llaman objeto parcial: seno materno, excremento y su equivalencia metafórica: oro, materia constituyente y soporte simbólico de todo barroco-, mirada, voz, cosa para siempre extranjera a todo lo que el hombre puede comprender, asimilar(se) del otro y de sí mismo, residuo que podríamos describir como la (a)lteridad, para marcar en el concepto el aporte de Lacan, que se llama a ese objeto precisamente (a) (1999: 1401-2).

57 En realidad, en lugar de restringir, estos criterios terminan dispersando el concepto de barroco. Lo que no hay que deplorar. "El barroco y el neobarroco" tiene algo de manifiesto y como en todo manifiesto, el texto adopta un tono más programático que argumentativo. Con la desarticulación del signo lingüístico y la reflexividad Sarduy define menos las características de cierta vanguardia latinoamericana que los atributos de la literatura en general, concebida como un lenguaje autónomo y autotélico que se opone al lenguaje comunicativo. El tercer criterio es un mucho más enigmático. ¿Qué quiere decir exactamente que el espacio barroco, espacio de derroche y de la superabundancia, se complace en la búsqueda por definición frustrada del objeto parcial? ¿De qué manera se vuelven a cruzar, a través de la noción de barroco y objeto $a$, las letras y el inconsciente?

Como su nombre lo indica, el objeto $a$ es antes que nada una letra, que forma parte de la amplia familia de objetos concebidos por el psicoanálisis. El objeto $a$ está emparentado con el objeto perdido de Freud (tal como aparece descripto en la teoría del sueño, la melancolía o en el juego del Ford-Da); los objetos parciales que descubren Karl Abraham y Melanie Klein, como el seno o las heces, recortados por las pulsiones parciales de ciertos bordes y orificios de la superficie del cuerpo, como la boca y el ano, entre otros; el objeto transicional de Winnicott (peluche, pedazo de trapo, almohada que representa a madre y que ayuda al lactante a soportar la separación, creando un espacio intermedio entre el mundo interior y el mundo exterior, el espacio transicional que hace posible el juego, las artes, las ciencias y las letras). En Lacan, el objeto a fue tomando a lo largo de su obra diversas acepciones, representaciones, manifestaciones y traducciones, según se lo piense desde el deseo, la pulsión, el fantasma o el goce. Es el objeto de amor que Platón describe en el Banquete, el objeto que Alcibíades busca en Sócrates, el ágalma (objeto precioso, ornamento, joya, estatuilla que se ofrece a los dioses) guardado en un sileno (embalaje tosco). Es el objeto que cae, cuando el sujeto se separa del Otro, como un residuo, deshecho o resto que no se deja simbolizar, como el remanente que irrumpe cuando se introduce lo simbólico en lo real. Es también el objeto del deseo, pero no tanto el objeto hacia el cual apunta el deseo, sino el objeto que 
lo causa y lo orienta desde una inadecuación radical: un objeto que se sustrae y un objeto sustraído. El objeto a es, en definitiva, una falta de objeto, un objeto definido a partir de una no identidad consigo mismo, como el cero.

Definir el neobarroco en relación al objeto a equivale a poner en relación la literatura con el límite de lo que no se puede decir, el límite de lo que no se deja simbolizar, el límite de lo que escapa al sentido. La lengua es algo más que una cadena de significantes disociada de una cadena de significados. Siempre hay algo que le falta y la descompleta; algo que resiste y que se escurre; algo que las palabras no pueden decir. La lengua está agujereada y la literatura no es sino el arte de acomodar un vacío.

Para el neobarroco, el sentido es un objeto perdido. En lugar de obturar y suturar este vacío, la literatura neobarroca prefiere contornearlo, circunscribirlo, dar vueltas alrededor de sus bordes. En el neobarroco, no se trata de descifrar un acertijo oscuro, como en el barroco. Al principio, no hay un significante ausente, disimulado, escondido detrás de otro, que un lector agudo podría llegar a descubrir, descifrar y traducir. Lo que hay al principio es un vacío de sentido, que nada puede colmar y que solo se puede bordear, reduciendo las palabras a un residuo, desbaratando toda tentativa de captura.

61 Si los ríos del esquema de Libertella van a dar al neobarroco, es porque al pie del árbol hermético, hay un agujero, hacia el cual se precipitan las letras. La literatura hermética contornea estas letrinas del sentido. En estas circunstancias, el sentido solo puede aparecer como sentido perdido, fuga de sentido, desecho de sentido, sin sentido. Por eso mismo, en este retrato de familia, Libertella incluye en las relaciones de parentesco neobarroco no solo a sus ficciones teóricas, sino también a ciertas manifestaciones glosolálicas, que representan la utopía de un significante desprovisto de significado, de un sinsentido que provoca el sentido como efecto residual, como es el caso de los grafismos asémicos de Mirtha Dermisache, el idiolecto de Jorge Bonino o las afasias. Libertella escribe: "En esta botánica que prolifera, ¿no será la literatura la que se siente una fruta madura y abúlica a la que nada le importa, salvo caer bien cómoda en el cesto del texto, in tiesto, tiesa, terca y testaruda, como decir: estiércol?" (1993: 70).

\section{El juglar hermético y Tamar}

El 4 de julio del 2000, unas semanas antes de dar a la imprenta El árbol de Saussure, Héctor Libertella desliza debajo de la puerta de Tamara Kamenszain, por entonces su ex-esposa, una hoja formato A 4 donde se puede leer: 
Tamara: emerjo de un sueño con la máxima cantidad de anagramas y combinaciones de tu nombre. ¿Tanta cantidad de bolsones semánticos pueden esconder 5 letras?

TAMAR

\section{A Marta Marat}

Arma trama, Ama:

¡ara mar!

Ata rama



mata rata

(mata tara)

Ramat, $2 / 7 / 2000$ Kamenszein confiesa:

Tamar es una coda a El arbol de Saussure. Libertella escribe, a la manera de un juglar hermético, un poema anagramático llevando hasta el límite el procedimiento de composición que Saussure creyó descubrir en la poesía indoeuropea. El principio numérico y el principio temático se condensan en un principio cabalístico: todas las letras del poema no son más que la permutación de un nombre propio de cuatro letras $(t, a, m, r)$. En lugar de disimular, el poema exhibe su procedimiento de construcción.

El hermetismo puede desacomodar y fascinar, pero también frustrar e irritar. Tamara

Y así fue como el poema "Tamar", si es que realmente atesoraba alguna clave destinada a mí -Tamara-, había fallado en su cometido. Porque al poco tiempo de separarnos y después de no haber intercambiado más palabras que las estrictamente necesarias y burocráticas, yo esperaba de mi exmarido algún mensaje contundente del tipo "te extraño", "volvamos", "estoy dispuesto a cambiar", algún dardo en una lengua efectiva o, mejor dicho, afectiva, como esa que Philip Roth dice que usaba su padre, "una lengua apoética, expresiva y a bocajarro, con todas sus flagrantes limitaciones y toda su fuerza perdurable" (15-16).

El dardo verbal lanzado por el juglar hermético estaba escrito en una lengua demasiado sibilina como para dar en este blanco. El poema no llegó a destino. La destinataria no estaba en aquel momento con ánimos para descifrar estas lacanerías. Quería recibir una carta de amor que Libertella nunca escribió; o que tal vez sí escribió, pero que envió a una dirección equivocada. Es lo que siempre ocurre con las cartas de amor. Nunca llegan a donde tiene que llegar, siempre llegan demasiado pronto o demasiado tarde, con un mensaje que no coincide con el mensaje que se espera leer. La lectura y la escritura no son actividades simétricas y suplementarias. Al contrario, están marcadas por la divergencia y la no-correspondencia.

El tiempo de la escritura no coincide con el tiempo de la lectura. El poema es archivado en un cajón. En la catacumba de las fotografías y los papeles muertos, lleva una vida larvaria durante quince años, hasta el día en que la destinataria da con una clave en un 
ensayo de Julia Kristeva que le permite leerlo. Esta referencia, por supuesto, no es gratuita. Tamara Kamenszain y Héctor Libertella formaron en los años 70 una pareja militante del formalismo duro y puro, bebiendo el lento destilado del psicoanálisis, la lingüística y Tel quel, en el happy hour de Literal. Treinta años más tarde, la teoría literaria, el psicoanálisis lacaniano y la pareja militante textualistas colapsaron, pero las pasiones, que son indestructibles, siguen produciendo efectos que irrumpen ahí donde menos se los espera. Para leer el poema anagramático, la clave de lectura viene de Kristeva y no de la Kristeva de Sémiotiké, que fabrica una teoría del poema a partir de la teoría de los anagramas de Saussure, sino de la Kristeva ensayista de los 80, autora de Histoires d'amour. Este desplazamiento marca el cambio de época y de los libros que se apilan sobre la mesita de luz.

En Histoires d'amour, Kristeva escribe que la poesía de los trovadores del siglo XII estaba fundada en un tabú. Bajo ningún pretexto y en ninguna circunstancia, el nombre de la dama podía ser revelado en el poema, sin comprometer su honra y perfección. Este tabú le permite a Tamara Kamenszain leer el poema anagramático de Libertella como "un genuino poema de amor que, como los de los trovadores cortesanos a la puerta de un palacio, dice y oculta al mismo tiempo el nombre de una dama" (81).

A partir de esta clave, Tamara Kamenszain lee Tamar y escribe el Libro de Tamar, donde vuelven a cruzarse el inconsciente con las letras. Lo que importa no es tanto lo que se dice sino lo que se hace. Más allá de las referencias explícitas al psicoanálisis, Tamara Kamenszain desglosa el poema que emerge de un sueño de Libertella, como si fuera un sueño propio. Descompone el poema en segmentos y se abandona a las asociaciones que cada segmento le despierta, para develar aquello que esconden, como lo hace Freud en la Interpretación de los sueños, al analizar el sueño paradigmático de la inyección de Irma.

69 A la cábala centrífuga del jugar hermético, que al escribir expande un máximo de sentido con un mínimo de letras, corresponde la cábala centrípeta de la Dama, que al leer circunscribe la proliferación anagramática a un perímetro preciso, abotonando unas palabras con otras, para descifrar un mensaje que le fue destinado, como si hubiera algo que entender, descifrar o traducir en la opacidad de las letras. Recostada en el diván de la literatura, Tamara Kamenszain aspira a "develar algo de lo que esconde eso que él llamó bolsones semánticos" (14). Los bolsones semánticos, de hecho, están agujereados y no esconden ni contienen nada, a no ser el vacío de sentido. Poco importa. Todo tiene sentido, sobre todo el sinsentido. Todo es interpretable, sobre todo los mensajes herméticos, que en su resistencia a la interpretación, generan un deseo de interpretación. Tamara Kamenszain abrocha los signos ebrios del poema anagramático en una novela matrimonial, que es también la novela de una época y sus pasiones teóricas. No solo escribe, sino que también lee en primera persona del singular y del plural. Al y/o de Libertella, contrapone otra gramática de los pronombres personales, "para decir por fin en verso/algo que vuelva a juntarnos a mí/a ti, a él, a ella/en un nosotros tardío" (37). Le hace decir a Tamar aquello que el poema no puede formular directamente, por ejemplo la palabra amor. En la lengua anagramática del juglar hermético, falta la $o$.

70 Pero lo propio de las cartas de amor es que nunca pegan aquello que se despegó, nunca unen lo que se divorció, nunca ayudan a recuperar aquello que está irremediablemente perdido. Tamara Kamenszain lo reconoce: la novela matrimonial no puede ser tramada. A lo sumo, el ejercicio la ayuda "como escritora a cuatro manos, a liberarme de dos" (84). Las divergencias y la no-coincidencia entre la escritura y la lectura no están 
exentas de efectos. El signo ebrio provoca, como se provoca una pelea o un deseo. El signo ebrio provoca el deseo y la pelea del sentido. Una manera de leer lo que no se deja leer es escribir para disolver y digerir el cuerpo extraño del sinsentido. El poema que cierra El libro de Tamar dice:

Entonces yo me pregunto en nuestro caso

si cinco letras pueden decirte a vos lo que me dejaron

de decir a mí o al revés si a lo mejor yo

les hago decir ahora más de lo que pueden

para que nos unan a la fuerza

como quien encuaderna en uno dos libros. (86)

\section{BIBLIOGRAPHY}

Cifali, Mireill, « Une glossolale et ses savants : Élise Muller alias Hélène Smith », La Linguistique fantastique, Sylvain Auroux et al. (ed.), Paris, Denoël, 1985.

Damiani, Marcelo (ed.), El efecto Libertella, Rosario, Beatriz Viterbo, 2010.

Flournoy, Théodore, Des Indes à la planète Mars, Marina Yagüelo y Mireille Cifalli (ed), Paris, Éditions du Seuil, 1983 [1900].

Kamenzain, Tamara, El libro de Tamar, Buenos Aires, Eterna Cadencia, 2018.

Lacan, Jacques, “Instance de la lettre dans l'inconscient ou la raison depuis Freud”, Ecrits, Paris, Ed. du Seuil, 1966.

---, "Instancia de la letra en el inconsciente o la razón desde Freud", Escritos, Buenos Aires, Siglo XXI, 2002 [1971]. Traducción de Tomás Segovia.

---, Le séminaire, livre VIII: Le transfert, Paris, Ed. du Seuil, 2001.

---, Le séminaire, livre X: L’angoisse, Paris, Ed. du Seuil, 2004.

---, Le séminaire, livre XI: Les quatre concepts de la psychanalyse, Paris, Ed. du Seuil, 1973.

---, Le séminaire, Livre XX: Encore, Paris, Ed. du Seuil, 1999, [1975]

Lacoue-Labarthe, Philippe y Nancy, Jean Luc, Le titre de la lettre, Paris, Galilée. 1973.

Libertella, Héctor, Ensayos o pruebas sobre una red hermética, Buenos Aires : Grupo Editor Latinoamericano, 1990.

---, Las sagradas escrituras, Buenos Aires, Sudamericana, 1993.

---, El árbol de Saussure. Una utopía, Buenos Aires, Adriana Hidalgo, 2000.

---, La arquitectura del fantasma, Buenos Aires, Santiago Arcos editor, 2006.

Libertella, Héctor (ed.), Literal 1973-1977, Buenos Aires, Santiago Arcos editor, 2002.

Ludmer, Josefina, Aquí América: una especulación, Buenos Aires, Eterna Cadencia, 2010.

Milner, Jean-Claude, L'amour de la langue, Paris, Ed. du Seuil. 1978.

---, Le périple structuraliste, Paris, Verdier. 2008. 
Sarduy, Severo, "El barroco y el neobarroco", América Latina en su literatura, César Fernández Moreno (ed), México, Siglo XXI, 1972, p. 167-183.

---, "El barroco y el neobarroco", Obras completas, vol 2, Gustavo Guerrero y François Wahl (ed.), Madrid, ALLCA XX, 1999.

---, Barroco, Obras completas, vol. 2, Gustavo Guerrero y François Wahl (ed.), Madrid, ALLCA XX, 19996.

---, Nueva inestablidad, Obras completas, vol. 2, Gustavo Guerrero y François Wahl (ed.), Madrid, ALLCA XX, 1999c.

Saussure, Ferdinand, Cours de linguistique génerale, Paris, Éditions Payot \& Rivages, 2016 [1916].

---, Curso de lingüística general, Buenos Aires, Losada, 2007 [1941]. Traducción de Amado Alonso.

Starobinsky, Jean, Les mots sous les mots. Les anagrammes de Ferdinand de Saussure, Paris, Gallimard, 1971.

Todorov, Tzvetan, Théorie du symbole, Paris, Ed. du Seuil, 1977.

\section{ABSTRACTS}

This article deals with the relationship between linguistics, psychoanalysis and literature: the friction-laden crossover of the unconscious to language over three distinct time periods. First, the beginning of the 20th century when, as Ferdinand Saussure is studying anagrams in IndoEuropean poetry, Theodore Flournoy asks him to evaluate the somnambulist glossolalia produced by the medium Hélène Smith. Then, the middle of the 20th century, when Jacques Lacan, in the wake of structuralism, revises the Saussurean linguistic sign from the perspective of the Freudian unconscious. Finally, at the end of the $20 \mathrm{~h}$ century, when Hector Libertella reinvents the hermetic vanguard through a reading of Lacanian theory, wittily recasting in his theoretical fiction El árbol de Saussure the linguistic sign as the inebriated sign.

"El signo ebrio" intenta pensar, a partir de la ficción teórica de Héctor Libertella El árbol de Saussure (2000), las relaciones que pueden establecerse entre la lingüística, el psicoanálisis y la literatura, cuando se cruzan no sin conflicto la lengua, el inconsciente y las letras. El artículo aborda tres momentos de este cruce: el principio del siglo XX, cuando Saussure estudia los anagramas en la poesía indoeuropea y Flournoy le pide que examine las glosolalias sonambúlicas de la médium Hélène Smith; la mitad del siglo XX, cuando, en medio de la efervescencia estructuralista, Lacan reformula la teoría del signo linguístico de Saussure a partir del inconsciente freudiano; y las postrimerías del siglo XX, cuando Libertella piensa las vanguardias herméticas a partir del psicoanálisis lacaniano y reformula humorísticamente la teoría del signo lingüístico como signo ebrio.

A partir d'une lecture de El árbol de Saussure, fiction théorique d'Héctor Libertella publiée en 2000, cet article se propose de réfléchir aux relations entre la linguistique, la psychanalyse et la littérature, à travers l'articulation toujours équivoque entre le langage, l'inconscient et les lettres. Trois moments de ce croissement sont abordés : le début du XXe siècle, lorsque Saussure s'intéresse aux anagrammes de la poésie indo-européenne et que Théodore Flounoy lui demande d'étudier les glossolalies somnambuliques de la médium Hélène Smith ; la seconde moitié du XXe siècle lorsque Jacques Lacan, dans le sillage du mouvement structuraliste, reformule le concept de signe linguistique de Saussure depuis l'inconscient freudien; la fin du XXe siècle, lorsque 
Libertella réinvente les avant-gardes hermétiques à l'aune de la psychanalyse lacanienne et reformule de façon humoristique la théorie du signe linguistique en termes de signe ivre.

INDEX

Mots-clés: signe linguistique, anagramme, inconscient, baroque, avant-garde hermétique Palabras claves: signo lingüístico, anagrama, inconsciente, barroco, vanguardia hermética Keywords: linguistic sign, anagram, unconscious, baroque, hermetic vanguard

\section{AUTHOR \\ DIEGO VECCHIO}

Université de Paris 8 Vincennes-Saint Denis dievecchio@gmail.com 